DOI: $10.2478 /$ rpp-2018-0007

$\mathrm{PhD}$, Senior Lecturer, SERGO KURULISZWILI

The Maria Grzegorzevska Academy of Special Education Address: 40 Szczesliwicka St., Warsaw, 02-353, Poland E-mail: sergo@aps.edu.pl

\title{
THE CHANGE OF PERCEPTION, RECEPTION AND THE SOURCE OF INFORMATION AMONG GENERATIONS BORN IN 1990S THROUGH THE PRISM OF FOREIGN SCHOLARS' VIEWS
}

\begin{abstract}
Constant ICT development brings new channels of communication and new forms of media content. It creates new habits of information consumption. This is evident particularly among children and students. Their perception and reception influenced by quality and quantity change is evolving. There is a significant change in the process of information selection and its absorption. The time of learning is not limited to school activity; homeworking is constant along with other life activities. It generates new challenges for educational system mainly for teachers. The article is an attempt to describe this phenomenon and formulate some directions for teachers - method suggestions as well as a tool selection. The content of the article is based on the outcomes of the author's research. Indications addressed to teachers whose daily work is most affected by the new situation with ICT have been formulated. In the process of study the following pragmatic conclusions have been made: children and adolescents are accustomed to receiving short interactive content; the amount of information that reaches the youth is vast and requires an ability to assess and choose; in order to draw the recipient's attention, the content should be communicated in an interactive form that is highly attractive for the recipient; children and adolescents far more often use content that is available online than that from other sources of information; work with more lengthy texts and an in-depth content analysis is necessary for the proper development of both children and adolescents despite being unpopular among these groups; children and adolescents have a valuable ability to shift focus from one subject on another, though their capacity to multitask is only apparent; children and adolescents expect their actions to give rapid results; children and adolescents have a competence potential and a technical potential to use IT tools that facilitate access to information and learning; due to the vast number and the diversity of available activities a stronger motivation to learn in required. An inventory of recommendations addressed to teachers has been also presented in the paper. It has been defined that their delivery will facilitate the implementation of teaching tasks, hence diminishing the concerns that arise in this regard.

Keywords: ICT, e-learning, technology in education, media in education, educational content perception, educational content reception.
\end{abstract}

\section{INRTODUCTION}

By implementing educational programmes, teachers are faced with a very difficult issue. The problem pertains to the ways of teaching and educating in the reality shaped by new, rapidly growing media. The changes arising from the development of information technology determine nearly all aspects of life, including learning processes. Hence, this issue requires an analysis, while didactic methods need to be updated. 
Despite being commonly discussed, the problem requires permanent changes resulting from ongoing analyses and adaptations, whereas the complexity of this matter calls for a differentiated approach.

\section{THE AIM OF THE STUDY}

In the presented article an attempt has been made to analyse the essential elements that determine educational reality in the context of changes in the perception and reception of information, and changes in the trends of their choice among the young generation. This fragment of transforming reality has a significant impact on teachers' work.

\section{THEORETICAL FRAMEWORK AND RESEARCH METHODS}

The author's deliberations were inspired by findings obtained during his studies, part of which is presented in the article. The discussed issue should not be regarded independently of the context of the overall changes that take place. Therefore, other determinants of the development of school didactics are indicated first. Research was conducted on the group of Polish students. The framework of discussion was based also on the study of international bibliography focused on the problem of cybermedia in society and education.

\section{RESULTS}

The fundamental phenomena resulting from the development and popularisation of "new new media" (nowe nowe media) (Levinson, 2010) that impact the "pedagogical reality' can be expressed in the list below:

- a vast amount of information reaching both teachers and learners, which is difficult to handle;

- a change in the way of transmitting information and in the form of information (changes in information channels);

- changes of attitudes adopted by recipients (learners);

- reduced impact exerted by teachers on the content that forms the learners' knowledge and foundations - the issue of the quality of information;

- "time competitiveness";

- permanent, rapid and easy access to information.

The first three characteristics of the present-day reality require no commentary, as these issues have been repeatedly discussed, mainly in pedagogical literature (Bauman, 2007; Carr, 2010).

It is relevant that three characteristics of modern educational reality (namely the fourth, the fifth and the sixth ones) are briefly explained, the latter acting as an axis for deliberations on changes in the perception and forms of choosing information sources by young individuals.

Traditional education includes preparation or determination of information sources that specify and explain the subject being learned. Usually, it consists of various didactic materials, oftentimes in the form of texts, but also multimedia content. The choice of materials is the key element of the teaching process. This kind of support is typical of every process of guided self-education and teaching. The search for content that would facilitate this process in the "ending pedagogical era" before the "new new media" pertained primarily to printed materials usually subjected to verification either by the editor or the publisher. At present, due to the high accessibility of materials in electrical forms, widely available also due to the fact that publishing has been made easy, learners seek this kind of content on their own initiative, in most cases driven by Google "hits" instead of the teacher's references. Consequently, the content that becomes involved in the learning process may be of poor quality due to their invalidity, lack of objectivity or incompleteness. 
In extreme cases, information acquired on one's own on the web may prove contradictory to the information provided by the teacher. This may lead to conflict and compromise the teacher's authority. In the new situation, the teaching content is selected by at least three parties, namely: the teacher, the learner who seeks information online unassisted, and mechanisms that determine search engine results (to simplify search engine algorithms, e.g. Google, as well as the structure and tags of a given website). Until now, the teacher placed in the triad "the teacher/school, parents/caregivers, peers" was the sole person fundamentally responsible for choosing the teaching content (according to guidelines). At present, this role is substantially limited.

"Time competitiveness" is a concept created for the purposes of this article that refers to the quantity of potential activities or activities undertaken by learners with regard to their individual time constraints. The emerging diversity that has not been experienced before to this extent together with the very high accessibility of activities and content blogs, Television series, games, magazines, social media - were formed primarily due to the possibilities offered by the world wide Web 2.0. In this sense, mass culture (popculture) is exceptionally competitive with the education system. Due to the significantly higher development and amusement production expenditures compared to education costs together with the high accessibility of amusement media, the educational system loses this competition. The missionary character of education stemming from its positivist context deprives it of the possibility to function an on equal footing with the omnipresent amusement.

The vast diversity and expansive nature of the media (the so-called "push media" or aggressive media) enforce need for an ongoing selection process, i.e. choosing between tempting attractions and duties, education and work. Adults are faced with the above choice as well. However, this choice has a slightly different nature for Generation Z. Online activities have been embedded in their daily life since childhood. The aspect of activity is not a subject of choice, as they choose items and people without due account of the aspect of contact, a kind of mediation. For adults, the dividing line in their choices often runs between the real world and the virtual one - a medium, which does not take place in the case of children and adolescents. Insufficient time is a characteristic of the majority. It has a considerable deterring impact on the teacher's work, who competes with various other attractive forms of passing one's time in his or her attempt to spark students' interest. Competitiveness must also characterise the content proposed by the teacher. Such a phenomenon, which occurred in the past as well, has considerably intensified at present. The significant impact of pop-culture on the teaching process has been noted by numerous authors: (Melosik, 2012; Melosik \& Szkudlarek, 2010; Savage, 2008; Tisdell \& Thompson, 2005). Still, the problem persists for teachers.

The findings obtained by the author in the course of his original studies (2016/2017) have encouraged considerations on the issues related to the dynamically changing teacher's role and challenges that are yet to be faced by both the counsellor as an artisan who teaches and shapes his or her students, and by didactics itself, which provides him or her with tools and methods.

Studies conducted on a group of 87 students were arranged as a general superficial diagnosis that allowed the author to analyse behaviours related to seeking information both with the aim to solve daily problems and those essential for improving one's competencies and knowledge. Selected findings that act as an impulse for reflection on the teacher's role and tasks in the context of the expansion of new media are presented below. 
Over $90 \%$ of the respondents seek information on the Internet every day, $60 \%$ of whom do it multiple times a day. Since these results are consistent with the observations made in the course of other studies and the obtained findings, they are not surprising. The Internet has been accompanying humanity on almost permanent basis. However, the declared priority of specific information sources sought by the respondents seems disturbing. As many as $47 \%$ of the study participants claim to seek information in libraries or bookstores as a last resort. Nearly $53 \%$ state that teachers serve as their last source of information. Over $20 \%$ declare to never seek teachers' help when searching for information, while a quarter of the respondents claim to seek information elsewhere than in libraries and bookstores. Probably, when answering the last questions (spes ultima moritur), they fail to give due account of required reading recommended in the course of their education. As many as $62 \%$ of the study participants name the Internet as a source of information of first choice, $34 \%$ declare to often use the web to find information they need. Traditional "analogue" sources of information are being replaced by online content. Importantly, a considerable group of the respondents turn to their friends and colleagues for support in solving a problem, with $59 \%$ resorting to this method often and nearly $23 \%$ seeing it as a measure of first choice. The survey questionnaire provided no information on how students reach to their friends or colleagues for help. Perhaps this takes place via the Internet.

The respondents' expectations regarding the information found online are mostly satisfied. As many as $76.5 \%$ declare that they often succeed in finding the information they seek, whereas nearly $20 \%$ claim they always do. Only $5.8 \%$ of the respondents stated that the found information allows them to fully solve the problem, whereas over $88 \%$ claimed that it is very helpful. No respondent indicated that it facilitated the solving of the problem only to a small extent or that it proved useless. The sources of information explored by the learners (mainly the Internet) are considered valuable and sufficient.

Nearly $90 \%$ of the study participants specified the information sought online to pertain to daily activities. As many as $72 \%$ indicated knowledge required for the learning process (studying). Internet provides them with the information necessary in each situation of cognitive deficit.

The process of seeking information online is described by the respondents as learning (78\%). As many as $62 \%$ indicate that it is "a learning process to a large extent", while $17 \%$ consider it "definitely a learning process". According to only $6 \%$, this type of information seeking (either rather or definitely) cannot be classified as a learning process.

A single incidental act of information seeking takes less than 15 minutes in the case of over half of the study participants, $59 \%$ of whom spend less than 5 minutes on searching information online, while $41 \%$ spend as much as 15 minutes. At the same time, a quarter of the respondents declare situations where the mentioned process takes up to 30 minutes. Only $10 \%$ note incidents where this process takes over an hour.

The above results indicate that single acts of obtaining information are brief, i.e. incidental e-learning. "Incidental e-learning is a new form that appeared concurrently with evolving Internet. Learning in various aspects of life, which facilitate the solving of both daily problems and professional issues, lies in seeking and perceiving various materials available in different forms online. The content is usually unrelated, as it comes from different sources, while the criterion for selecting results are subject-related "hits" in a given web search engine. The level of their popularity is determined by their position on search engine websites. Incidental e-learning becomes a permanent form of extending one's knowledge and gaining skills (Kuruliszwili, 2016). 
The most popular type of online information resources specified by the respondents is a website, followed by Internet forums and video-sharing websites, such as YouTube. According to the study, as many as $56 \%$ of the study participants use websites often, while $26 \%$ of them use websites occasionally.

The obtained results are compliant with the findings provided by other studies, including Nastolatki wobec internetu ("Adolescents and the Internet") (Bochenek, Fila, Kamieniecki, Lange, Loba, Tanaś, \& Wrońska 2016), according to which $34.1 \%$ lower secondary school students and $38.7 \%$ upper secondary school students claim to use the Internet on daily basis for doing homework assignments, whereas $39.5 \%$ and $45 \%$ of them, respectively, use it several times a week. (Bochenek, Fila, Kamieniecki, Lange, Loba, Tanaś, \& Wrońska 2016) The willingness to apply the web in learning (homework assignments) is intrinsic. The above-mentioned research of NASK indicates that students in general do not claim to have participated in a situation where a teacher encourages them to use the Internet. Only 14\% stated that teachers encouraged them to use the web for doing their homework assignments (Bochenek, Fila, Kamieniecki, Lange, Loba, Tanaś, \& Wrońska 2016). This is confirmed by results of the 2013 study Nowe media w polskiej szkole ("New media in Polish school"). The results indicate that over half of the teachers participating in the study, i.e. $46.9 \%$, have never sent their students teaching materials online, whereas 20.7 $\%$ of the teachers claimed to do it once a month. (Batorski \& Jasiewicz, 2013) Interestingly, similarly to students, teachers seek information on the web as well. Over $40 \%$ of the latter engage in online search on daily basis, while nearly $40 \%$ do it once or twice a week (Batorski \& Jasiewicz, 2013).

The research findings suggest that Internet has replaced other sources of information, particularly printed ones, for the mentioned group of respondents. The information obtained in this way is considered sufficient by students. The easiness and short time required to reach the goal, i.e. to learn something new, are very tempting. The common trait of the present-day youth is impatience in waiting for a result of the process of seeking information. Owing to mobile devices and increasingly better ICT infrastructure, a piece of information is often instantly accessible. In order to check the meaning of an unknown word, one does not have to go to a library or ask an expert. Owing to websites available via mobile network we can verify it instantly. The way of seeking information that is dominant in the study results, specifically incidental e-learning, is linked to the observed characteristic. The correlation between cognitive activity and the expected rapid result can take the form of a mutually detrimental vicious circle involving these elements. When seeking a rapid result, we resort to the Internet and become accustomed to obtaining results in no time, thus growing increasingly impatient and thus search for solutions online.

The criterion for choosing the source of information and the medium for communicating information is access duration, time for obtaining the result.

Some concerns arise with regard to the expectation of rapid results in the process of seeking information, which is notable in the group of students participating in the study and characteristic of young generations, and constitutes one of the traits that determine changes in the process of perceiving information. It is often the case that an articulated concern pertains also to a change in the way how the information in its new form is received. As a result of reading numerous short synthetic texts or receiving a high amount of brief information in a different form (a sound, an illustration, an animation, a video), the need for a more in-depth understanding of this issue decreases. This type of synthetic message is characteristic of present-day television and radio programmes, the press, news websites and advertisements. Accustomed to laconic messages, recipients no longer need to analyse the issue in more depth. 
According to Nicholas Carr, this situation may have a negative impact on the development of science and civilisation (Carr, 2010), thus causing a movement away from unassisted, in-depth analytical work and literature research that serve as the foundation of progress. Similar concerns were expressed by Manferd Spitzer (Spitzer, 2015).

Changes in the "information consumption" habits result in a shorter attention span and, moreover, in seemingly multithreaded nature of activities. When working on the computer, reading short non-complimentary texts provided in a non-linear manner, doing several activities seemingly simultaneously (reading e-mails, texting, listening to music, chatting via an instant messenger), one's attention is shifted from one thread to another. Hence, as the brain is being "accustomed" to the above, difficulties arise in relation to focusing on one text for a longer time. In reality, multithreaded activities are not implemented simultaneously.

The way of receiving information is shaped by the form in which it is communicated, as well. A text is oftentimes replaced by an image. Pictorial communication has dominated new media, as not only does it determine the receivers' perception and reception of information, but also affects the present-day reality, cultural cohesion that has been defined by language, a "linguistic turn" (Rorty, 1980). Turns of this sort, the dominant position of image in the culture of message that gives rise to its common and broad influence both on the shape and the dynamics of how culture is understood was specified years ago as a pictorial turn: "What makes for the sense of a pictorial turn, then, is not that we have some powerful account of visual representation that is dictating the terms of cultural theory, but that pictures form a point of peculiar friction and discomfort across a broad range of intellectual inquiry" (Mitchell, 1995). Regardless of how this change is defined, its implications concern numerous aspects of life and scientific areas. A particularly strong effect is exerted on didactics.

The formulated concerns pertain to a change of the habit regarding communication and forms of interpersonal contact. An interaction, made indirectly through an electronic medium, saps the youth's ability to establish interpersonal contacts.

The entity's changing perception in the learning process is characterised by a notably greater need for strong stimuli and interactions. This pertains both to the level of process initiation and the ability to maintain attention. Due to the vastness of information communicated in our environment, senders of the information have to move to outdo each other in order to reach the recipient, i.e. to draw attention to the broadcast information. The recipient can be reached effectively by means of providing information in the form of attention-drawing stimuli. A message of this sort has a desensitising effect on young recipients, thus making them less sensitive to more subtle forms of communication. Oftentimes, the message that reaches adolescents, particularly when transmitted via the Internet, has an interactive nature. Social networking sites, blogs or other forms of publication allow the recipients to comment or complement information, in line with the concept of Web 2.0. Using websites of this sort forms a need for interactivity in a message. This process seems impossible to be reversed, hence requiring one to adjust to the situation. Consequently, it should be taken into account in designing teaching actions.

The characteristics of the teaching entity indicated above are consolidated as a result of iterative actions caused by the occurrence of the factors listed in the Introduction and by brain neuroplasticity.

These numerous concerns, both among teachers and parents, constitute a reaction characteristic of each change. It is a natural social response to a new situation. 


\section{CONCLUSIONS}

The new educational reality is also a potential for new teaching possibilities. The ability to approach the problem observed among the youth in a synthetic way, new information channels, educational games (gamification), the easiness of creating attractive teaching materials or new (both in terms of quantity and quality) devices/applications at increasingly lower prices are characteristics that may improve the effectiveness of the educational process. This paper is summarised by indications addressed to teachers whose daily work is most affected by the new situation. As a starting point for specifying recommendations based on general findings of the above-described analysis, with due account of opportunities arising from the common accessibility of ICT, the following pragmatic conclusions were formulated:

- children and adolescents are accustomed to receiving short interactive content;

- the amount of information that reaches the youth is vast and requires an ability to assess and choose;

- in order to draw the recipient's attention, the content should be communicated in an interactive form that is highly attractive for the recipient;

- children and adolescents far more often use content that is available online than that from other sources of information;

- work with more lengthy texts and an in-depth content analysis is necessary for the proper development of both children and adolescents despite being unpopular among these groups;

- children and adolescents have a valuable ability to shift focus from one subject on another, though their capacity to multitask is only apparent;

- children and adolescents expect their actions to give rapid results;

- children and adolescents have a competence potential and a technical potential to use IT tools that facilitate access to information and learning;

- due to the vast number and the diversity of available activities a stronger motivation to learn in required.

The above conclusions pertain also to older individuals, e.g. college and university students. Due to a generation change, the specified characteristic will probably be assigned to subsequent generations.

In the article, other issues of lesser importance in this context, though highly significant, nonetheless, were intentionally omitted. These include: the quality of merit and the moral value of information, the problem of intellectual property, the teachers' IT competencies, information and communications infrastructure of educational establishments, or extreme pragmatic approach of the youth. The author's intent was to focus on the most significant matters centred around the axis of the problem defined as changes in the educational reality resulting from evolving form the communication and teachers' challenges thus implied.

The impact of the factors listed at the beginning of the article is continuous, whereas changes in the characteristics are of permanent nature. The evolution of the media is a permanent and irreversible process that requires accommodation. Oftentimes, the pace of these changes exceeds the adaptation rate. This leads to discomfort among participants of the process.

An attempt can be made to compensate the list of concerns and difficulties with a list of opportunities arising from the common access to information technology. An inventory of recommendations addressed to teachers is presented below. The delivery on the proposals listed below will facilitate the implementation of teaching tasks, hence diminishing the concerns that arise in this regard: 
- to use in the teaching process tools that are employed by students on daily basis (social networking sites, blogs, Wiki, instant messengers);

- teaching with the use of e-learning;

- to seek, create educational games that are possibly closest to those played by children and adolescents;

- to provide information in a brief synthetic form, at the same time promoting learning and encouraging learners to extend their knowledge on a given subject;

- to develop learners' ability to link treads, network resources and to apply the semantic web technology.

Sadly, application of the above possibilities, didactic opportunities is by no means a negligible challenge, particularly for teachers. However, such a challenge is better than a fear of the unknown. The ways of dealing with it is considered by us as the prospect of our future research.

\section{REFERENCES}

1. Batorski, D., \& Jasiewicz, J. (2013). Nowe media w polskiej szkole. Retrieved from http://pobierzwiedze.pl/wp-content/uploads/2013/11/Nowe-media-w-polskiej-szkole-wynikibada\%C5\%84.pdf

2. Bauman, Z. (2007). Plynne czasy - życie w epoce niepewności. Warszawa: Wydawnictwo Sic.

3. Bochenek, M., Fila, M., Kamieniecki, W., Lange, R., Loba, B., Tanaś, M., \& Wrońska, A. (2016). Nastolatki wobec internetu (Adolescents and the Internet). Warszawa: NASK.

York: Norton

4. Carr, N. (2010). The shallows: what the Internet is doing to our brains. New

5. Kuruliszwili, S. (2016). Technologie informacyjne a andragogika - edukacyjne wyzwania wspótczesności. Warszawa: Instytut Rozwoju Służb Społecznych.

6. Levinson, P. (2010). Nowe nowe media. Kraków: WAM.

7. Melosik, Z. (2012). Mass media, tożsamość i rekonstrukcje kultury wspótczesnej. In W. Skrzydlewski \& S. Dylak, (Eds.) Media - Edukacja - Kultura (pp. 31-49). Poznań; Rzeszów: Towarzystwo Technologii i Mediów Edukacyjnych.

8. Melosik, Z., \& Szkudlarek, T. (2010). Kultura, tożsamość i edukacja - migotanie znaczeń. Kraków: IMPULS.

9. Mitchell, W. (1995). Picture theory. Chicago: University of Chicago Press.

10. Prensky, M. (2001). Digital Natives, digital immigrants. On the Horizon, 9, 1-6. University Press.

11. Rorty, R. (1980). Philosophy and the mirror of nature. Princeton: Princeton

12. Savage, G. (2008). Silencing the everyday experiences of youth? Deconstructing issues of subjectivity and popular/corporate culture in the English classroom. Discourse Studies in the cultural politics of education, 29, 51-68.

13. Spitzer, M. (2015). Cyfrowa demencja. W jaki sposób pozbawiamy rozumu siebie i swoje. Słupsk: Dobra Literatura.

14. Tisdell, E., \& Thompson, P. (2005). The role of pop culture and entertainment media in adult education practice, Proceedings of Adult Education Research Conference. Kansas: State University Libraries New Prairie Press. 